\title{
PROGRAMA DE PREPARAÇÃO PARA APOSENTADORIA DA UERJ
}

\author{
Priscila Pinheiro Monzato
}

MBA em Tecnologia da Informação e Gestão de Projetos - Especialista em Educação Corporativa - Pedagoga Facilitadora de grupos de Preparação para a Aposentadoria e Palestrante no tema de Líder Coach Superintendência de Recursos Humanos (SRH) - Universidade do Estado do Rio de Janeiro $\bowtie$ pripmz@gmail.com/secap@srh.uerj.br

\section{Resumo:}

O Programa de Preparação para Aposentadoria (PPA) visa a auxiliar os servidores desta Universidade na reflexão, no planejamento e na construção de uma nova etapa que está por vir a partir da abordagem de diversos temas, possibilitando aos servidores a ressignificação da aposentadoria.

Palavras-chave: aposentadoria, preparação, educação contínua.

\section{Preparation Program for Retirement of UERJ}

\begin{abstract}
:
The Preparation Program for Retirement (PPR) aims to help employees of this University on reflection, planning and construction of a new stage that is coming from the approach many topics, enabling servers reframing retirement.

Palavras-chave: retirement, preparation, continuing education.
\end{abstract}

\section{INTRODUÇÃO}

O trabalho ocupa uma posição significativa na vida das pessoas, principalmente no que tange ao senso de produtividade e, pensando na aposentadoria como um estado de transição, de rompimento de um ciclo profissional, a equipe do PPA percebe como crucial o momento de preparação, pois é quando se discutem novas possibilidades e um planejamento para esta nova etapa. Momento esse que pode significar o encerramento de uma etapa da vida profissional, mas não necessariamente representa o desligamento da vida social, cultural, produtiva e afetiva. De acordo com apud Mendes et al. (2005 apud BOTH et al., 2012), "a aposentadoria provoca uma crise no indivíduo, pois, com o afastamento da vida competitiva, a autoestima e a sensação de ser útil reduzem-se."

A proposta do programa é auxiliar o pré-aposentado a se preparar para essa fase de mudanças, reorganizar a sua rotina para melhor aproveitamento do tempo, seja desenvolvendo novas atividades laborativas ou de lazer. A equipe considera o Programa como uma ação extremamente importante para apoiar o indivíduo que está prestes a se aposentar e não pode 
ficar isolado nesse processo, bem como contribui para a Universidade cumprir o seu papel social, dando apoio à comunidade e oferecendo uma atividade de extensão.

\section{HISTÓRICO}

O Programa de Preparação para Aposentadoria (PPA) da UERJ surgiu em 2007, quando a SRH realizou uma pesquisa com 70 servidores docentes e técnico-administrativos, aposentados no período de até cinco anos, para saber o impacto e a importância da implantação do mesmo. As entrevistas grupais que foram realizadas com esse grupo abordaram as seguintes questões:

- Como vocês vivenciaram este período da aposentadoria?

- A UERJ teria alguma contribuição a oferecer neste período?

- De que forma a UERJ poderia contribuir?

Embora a amostra não tenha sido, quantitativamente, representativa do conjunto dos servidores aposentados no período, consideramos que a participação do grupo ocorreu de forma bastante significativa e, além de tudo, espontânea.

De acordo com o retorno satisfatório desse grupo, as servidoras, uma Assistente Social e uma Pedagoga, que, na época, estavam coordenando a implantação do Programa, conseguiram a aprovação da ideia. Na época, o Superintendente de Recursos Humanos e o Diretor do Departamento de Seleção e Desenvolvimento de Pessoal acreditaram no impacto positivo que o Programa poderia gerar nos servidores e autorizaram a sua criação.

\section{PÚBLICO-ALVO}

O público-alvo é composto somente de servidores da Universidade do Estado do Rio de Janeiro, o que facilita a valorização e melhor compreensão das experiências individuais, além de estimular e fortalecer a criação de novos laços, pois os temas que são trabalhados abordam o contexto comum a todos os participantes.

Como pré-requisitos de atendimento são estabelecidos os seguintes critérios:

- Docentes e Técnico-Administrativos da UERJ com idade superior a: 
○ 48 anos para as servidoras;

○ 53 anos para os servidores.

Em caráter de exceção, oferecemos até duas vagas para os que já se aposentaram em até um ano, acreditando na possibilidade de novas contribuições para o grupo que está prestes a se aposentar.

\section{INSCRIÇÃOO}

As inscrições do programa ficam abertas durante o ano todo e são disponibilizadas no site da Superintendência de Recursos Humanos (www.srh.uerj.br), no link "Preparação para Aposentadoria".

Os canais de divulgação do Programa são diversificados, frequentes e atemporais, como por exemplo, os cartazes, a impressão no contracheque e no site da SRH. Os outros meios são utilizados, mas não de forma sistemática, como a Rádio Uerj, filipetas no estacionamento, folders nas Unidades e convites de pessoas que já participaram.

\section{ESTRUTURA}

O Programa é organizado e acompanhado pela equipe do Serviço de Capacitação da SRH, que vem se tornando multidisciplinar. Entendemos que é de suma importância a colaboração de pelo menos um dos profissionais da área pedagógica, psicológica e/ou assistência social e de que precisamos continuar estreitando os laços de parceria com as unidades para aproveitar os talentos internos da Universidade. Por isso, a maioria dos instrutores faz parte do corpo de funcionários e muitos já atuam no Programa desde a sua implantação.

Hoje, o formato dos encontros se dá em grupos de no máximo 20 pessoas, pois este é o quantitativo que consideramos suficiente para a integração e participação ativa de todos os integrantes, já que é um momento de escutarmos com atenção cada história, experiência e ideias, estimulando assim, novos olhares coletivos. Entendemos que é importante que o Programa esteja sempre evoluindo e tentando suprir as expectativas dos participantes, porém, merece a devida atenção sobre a importância de manter os temas essenciais e nunca perder o foco de oferecer informações necessárias para ampliar novos caminhos. 
Afinal, muitos servidores se sentem perdidos nesse momento de ruptura, os grupos apresentam sentimentos muito variados e confusos, retratando ansiedade, felicidade, tristeza, medo, nostalgia entre outros. Em relação ao planejamento, percebemos que os discursos giram em torno de micro aspectos como, por exemplo, viagens constantes, sem sequer avaliar outros aspectos, como a perda salarial que é sofrida nesse momento. E, nesse cenário, cabe à equipe conscientizar o grupo, proporcionando reflexão macro sobre os impactos que a aposentadoria gera em todos os aspectos da vida.

Como já dizia Zanelli e Silva, (1996, apud BOTH et al., 2012) "a perda do trabalho pode causar sérios prejuízos ao indivíduo, bem como desorientação emocional, desestruturação e sentimento de inutilidade". Cabe aqui, pensarmos na seguinte situação: se enquanto a vida profissional estava ativa o indivíduo recebia a palavra UERJ como um "sobrenome", dando uma sensação de pertencimento à Instituição, já com a aposentadoria, a quebra deste vínculo pode parecer uma "perda de identidade". Enquanto para outros, a aposentadoria pode ser vista como um presente para quem já se dedicou por tantos anos profissionalmente.

Os diversos sentimentos que essa fase desperta são abordados em dinâmicas e por diferentes instrutores com o intuito de mapear o estado atual, fazendo uma projeção para o futuro cenário. E, visando minimizar alguns desses impactos, o Programa oferece uma educação continuada, da seguinte maneira: durante o semestre acontecem dez encontros com temáticas diversas para o grupo de pré-aposentados e uma vez por ano acontece o Encontro Anual apresentando um assunto diferente do que já foi abordado para reunir todos os grupos que já participaram do PPA. Essa atividade tem como objetivo proporcionar novas informações, manter o contato com os servidores que contribuíram para o crescimento da Universidade por tanto tempo e fortalecer os vínculos entre todas as pessoas que já participaram do PPA, que, no momento, em sua maioria já estão aposentadas.

\section{METODOLOGIA}

Percebemos a pré-aposentadoria como um período muito significativo de adaptação íntima e singular, repleto de expectativas e mudanças que impactam os aspectos psíquicos, sociais, espirituais, físicos e financeiros. E, por isso, a metodologia deve pautar-se em alguns pré-requisitos, como: 
- promover discussão e reflexão sobre o período de aposentadoria;

- incentivar a conscientização da importância de se preparar para a aposentadoria;

- estimular a realização de planos individuais e coletivos;

- realizar atividades que despertem a devida atenção para essa mudança;

No primeiro encontro é aplicado um questionário para levantar o perfil dos participantes e, posteriormente, a consolidação é enviada para cada instrutor, para que possa direcionar o foco dos assuntos a serem discutidos, contemplando assim, a realidade de cada um. A equipe desenvolve um trabalho bem próximo do grupo e dos instrutores em busca de acompanhar as necessidades e tentar supri-las, manter a identidade do mesmo grupo até o final e dar suporte aos instrutores, quando necessário.

A metodologia adotada nos encontros visa a despertar o interesse para cada tema, informando os procedimentos pertinentes à nova etapa, facilitando a absorção dos conteúdos, estimulando, de preferência, todos os canais de aprendizagem, incentivando a construção coletiva e, principalmente, gerando correlação do conhecimento com as experiências que os participantes já possuem. Os instrutores trabalham com o grupo organizado em roda para possibilitar contato visual, normalmente usam slides, realizam atividades individuais e coletivas e, em alguns casos, atividades externas, quando propostas pelo grupo.

\section{TEMAS}

Figura 1 - Fluxograma "Preparação para Aposentadoria"

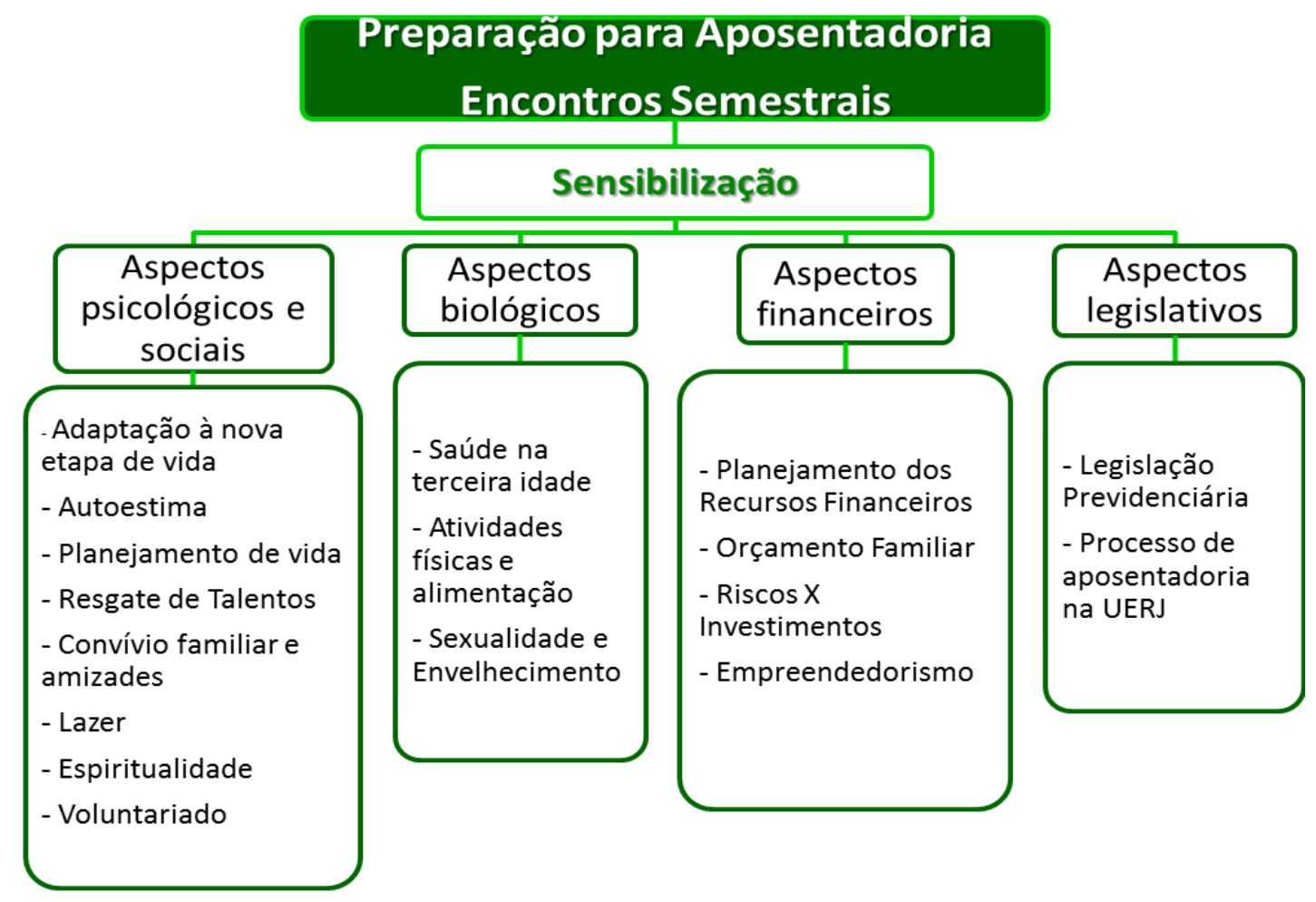


Atualmente, o nosso Programa apresenta uma abordagem completa trabalhando diversos aspectos pertinentes a essa fase. A Sensibilização, que acontece no primeiro dia, conta com a participação da equipe do PPA atuando como instrutores para promover a integração e a construção da identidade do grupo, explicando o formato e a proposta de trabalho. As temáticas abordam os aspectos a seguir,

1. Aposentadoria: etapa de grandes possibilidades - estimula o desenvolvimento de atitudes individuais e coletivas que favoreçam a autonomia física, mental, espiritual e social.

2. Planejamento de uma nova etapa de vida - trabalha com ferramentas para equilíbrio e planejamento da vida em todos os aspectos.

3. Lazer e tempo livre - estimula o aprender e/ou reaprender a como valorizar o tempo livre e delinear as futuras possibilidades quanto à administração desse momento.

4. Atividade Física e Promoção da Saúde - estimula nas pessoas um estilo de vida ativo para a saúde física e mental e seus benefícios.

5. Alimentação Saudável e Qualidade de Vida - apresenta os princípios da alimentação saudável baseados nos conceitos científicos da nutrição.

6. Legislação, previdência e processo de aposentadoria na UERJ - visa a orientar sobre os procedimentos que devem ser adotados para requerer a aposentadoria e a informar sobre a lei que rege a mesma.

7. Planejamento Financeiro - busca desenvolver o consumo consciente e a construção de uma vida financeira saudável.

8. Empreendedorismo - estimula o perfil empreendedor em relação aos conhecimentos que se deve ter para viabilizar a abertura do próprio negócio.

9. Pensando o Voluntariado - incentiva, através de um olhar humanizado, a prática da cidadania, pelo trabalho voluntário.

10. Lidando com emoções e sentimentos - proporciona reflexão sobre a aposentadoria através de teoria e prática sobre gerenciamento de emoções, sentimentos e pensamentos.

11. Convivência familiar - visa a abordar questões que possibilitem reflexões sobre o significado e tipos de família, a sua função e os modos de vida, enfatizando a construção desse convívio sob uma nova fase, que é a aposentadoria. 
12. Sexualidade e envelhecimento - discute acerca da sexualidade e das alterações no organismo no processo de envelhecimento.

13. Cuidando da Saúde na maturidade - apresenta as mudanças e consequências no organismo e sugere ações preventivas.

14. Resgate de Talentos - estimula um olhar sobre as próprias habilidades em busca de reconhecimento de novos talentos.

15. Espiritualidade - leva as pessoas a refletirem sobre os conceitos de espiritualidade e o estado de presença, as crenças, a missão e o propósito.

O momento de encerramento do Programa é conduzido pela equipe do PPA, que realiza o levantamento de satisfação através de atividades lúdicas e conclui o desenvolvimento do mesmo incentivando a continuidade dos vínculos.

\section{RESULTADOS}

Em 2007 foi formado um grupo com 20 pessoas para participar do projeto piloto e de 2009 até o momento, 2014.1, já passaram pelo Programa 126 servidores, sendo apenas 19 integrantes do público masculino e 107 do público feminino. As avaliações sempre foram muito positivas, com índices de efetividade de satisfação em torno de $80 \%$ a $100 \%$. No que tange ao Encontro Anual, a média de comparecimento ao evento é de $45 \%$.

Cabe aqui relatar algumas inquietações da equipe em relação ao público masculino. É comum que nos grupos ocorra uma pequena adesão por parte desse nicho, bem como alto índice de desistência (antes mesmo de conhecer o Programa) e de evasão (abandono ao longo dos encontros).

A maioria dos participantes demonstra imensa satisfação e se sentem muito valorizados pela equipe, que busca ouvi-los atentamente, apoia, na medida do possível, as necessidades do grupo, organiza os encontros com bastante atenção aos detalhes, mantém um contato bem próximo com os integrantes do grupo e acompanha o trabalho desenvolvido pelos instrutores em cada encontro. Como por exemplo, no dia do encerramento dos encontros semestrais, a equipe do PPA estimula que os participantes levem um acompanhante, que pode ser qualquer pessoa considerada especial para dar um depoimento sobre o impacto do programa na vida da pessoa que passou pelo mesmo. E tem sido uma experiência bastante significativa, pois comprovamos ainda mais a importância e o real impacto dessa proposta de preparar os pré-aposentados. Nesse dia, fazemos um fechamento sobre as questões que foram 
abordadas, realizamos atividades lúdicas (Figura 2) e reforçamos a importância de eles continuarem participando dos encontros anuais.

Figura 2 - Atividades Lúdicas (Programa de Preparação para Aposentadoria)

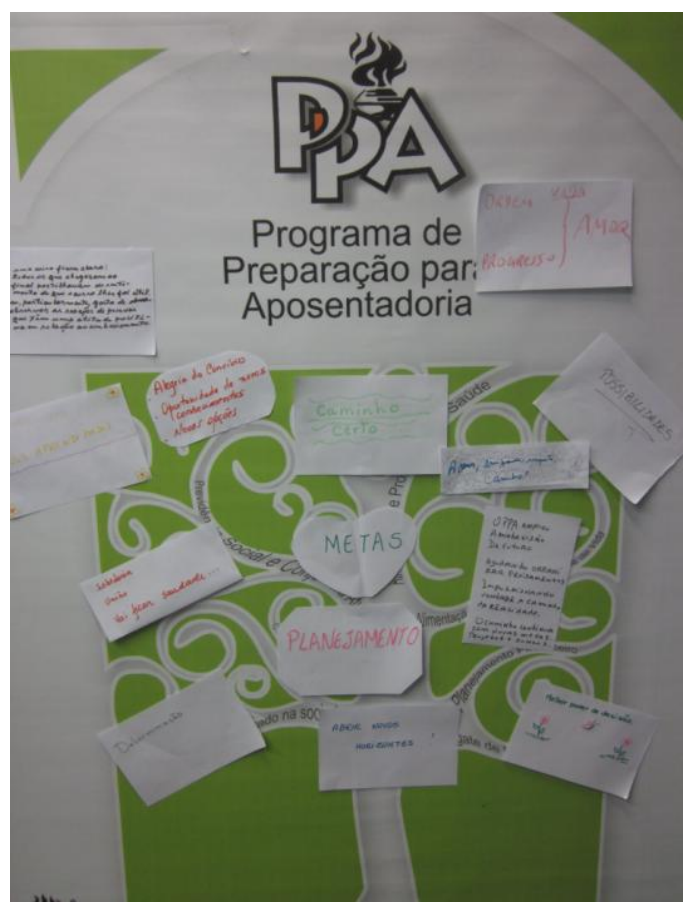

Dentre os temas que já foram trabalhados no Encontro Anual, "Espiritualidade" em 2011 foi o que mais atraiu o interesse, apresentando o índice de $61,3 \%$ de comparecimento conforme tabela 1. Devida à importância do mesmo incluímos esse tema nos encontros semestrais.

Tabela 1 - Encontros anuais do programa.

\begin{tabular}{cccc}
\hline $\begin{array}{c}\text { Encontros } \\
\text { anuais }\end{array}$ & Temática & Realização & Comparecimento (\%) \\
\hline 2010 & Promoção da Saúde & $06 / \mathrm{dez}$ & 35,3 \\
2011 & Espiritualidade & $24 / \mathrm{nov}$ & 61,3 \\
2012 & Memória & $27 /$ nov & 53,2 \\
2013 & Sexualidade & $12 /$ nov & 30,0 \\
\hline
\end{tabular}

\section{ANÁLISE DE DADOS}

A seguir, seguem os dados do Programa desde 2009 demonstrando o quantitativo atendido, em relação ao público feminino e masculino. Percebemos que a maior parte dos interessados são as servidoras e no geral, com perfil técnico-administrativo. A intenção é 
oferecer o encontro dos grupos uma vez por semestre, tendo em vista que sempre há lista de espera de pessoas que desejam participar do Programa.

Cabe aqui também citar que em um ano nove Instituições nos procuraram para benchmarking, dentre estas, uma foi para contribuir para uma dissertação de Mestrado sobre o tema PPA, duas para entrevistas e uma para apresentação do nosso Programa em um evento. Com isso, percebemos a valorização externa das nossas ações e do impacto positivo do Programa.

Gráfico 1 - Dados quantitativos do PPA de Atendimento ao Público Masculino e Feminino

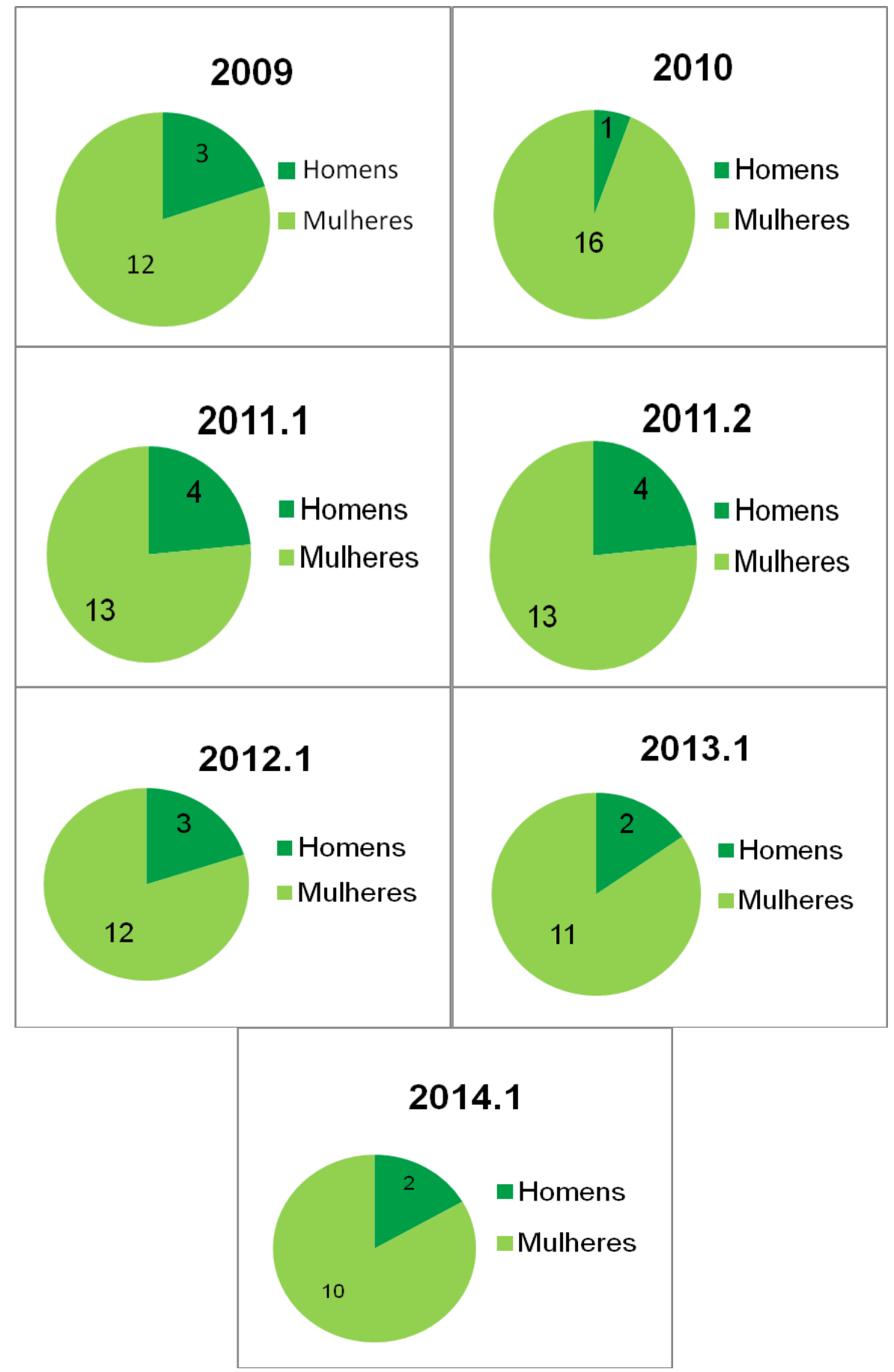




\section{VANTAGENS}

Percebemos que muitas são as vantagens para os servidores que participam desse momento de preparação, como, por exemplo:

- Receber informações pertinentes a essa nova fase;

- Ser auxiliado na tomada de decisão em relação à aposentadoria;

- Conhecer novas fontes de satisfação;

- Criar novos laços afetivos;

- Conhecer mais o que a Universidade tem para oferecer;

- Descobrir novos talentos;

- Melhorar a qualidade de vida;

- Desenvolver-se de forma contínua;

- Melhorar as relações interpessoais, sejam familiares, quando há o retorno para o lar, ou profissionais, quando ainda há a possibilidade de não se aposentar;

- Sentir-se valorizado enquanto servidor.

A equipe também enxerga que a Instituição que se preocupa em oferecer um Programa de Preparação para Aposentadoria recebe algumas vantagens, como, por exemplo:

- Exerce a responsabilidade social;

- Estimula a motivação do servidor, consequentemente elevando a disposição, comprometimento e a qualidade de vida no trabalho;

- Descobre os talentos internos;

- Fortalece as relações de trabalho;

- Melhoria da imagem externa à Instituição;

- Melhora o clima entre a equipe, quando há oportunidade de continuar trabalhando.

\section{CONCLUSÃO}

Sendo assim, trata-se muito mais do que uma preparação, pois a equipe busca dar continuidade às ações, de forma que o Programa não seja uma ação única. Além de auxiliarmos os servidores da UERJ na reflexão, no planejamento e na construção dessa nova fase que há de iniciar, buscamos estimular a construção coletiva de conhecimentos através de 
novos olhares, reunindo as experiências dos aposentados em momentos diferentes. Como também, ampliar o canal de divulgação dos eventos e atividades que ocorrem na Universidade.

Concordamos com o sentimento de satisfação e gratidão de poder colaborar com os servidores para transcorrerem de forma mais tranquila e consciente essa fase de transição e, principalmente de acompanhá-los nos encontros e perceber o quanto de valor agregado existe além de todo o conhecimento das temáticas discutidas, como as contribuições do grupo, o compartilhamento de experiências e sentimentos.

A equipe deseja que o Programa de Preparação para Aposentadoria faça cumprir o papel social da Universidade, apoiando os servidores nesse momento e estimulando para que seja uma etapa de construção de novos laços. E, esperamos também, poder continuar contribuindo com outras Instituições externas para troca de experiências e informações, incentivando assim, a multiplicação das nossas ideias e ações.

\section{REFERÊNCIAS}

BOTH, T. L.; KUJAWA, D. R.; WOLBETO, M. I.; SARAVIS, V. Consideração sobre o idoso aposentado: uma intervenção da Terapia Cognitivo-Comportamental como instrumento de preparação à aposentadoria. Revista Brasileira de Ciências do Envelhecimento Humano v. 9, s.1. Passo Fundo, 2012. p. 90-101.

FRANCA, L. Repensando a aposentadoria com qualidade: um manual para facilitadores de programas de educação para aposentadoria em comunidades. Rio de Janeiro: CRDE, UnATI UERJ, 2002.

FREIRE, P. "Ensinar exige curiosidade". In: Pedagogia da autonomia: saberes necessários à prática educativa. São Paulo: Paz e Terra, 1996, p. 84-90.

MENDES, M. R. S. S. B. et al. A situação social do idoso no Brasil: uma breve consideração. Acta Paulista de Enfermagem, São Paulo, v. 18, n. 4, p. 422-426, 2005 apud BOTH, T. L.; KUJAWA, D. R.; WOLBETO, M. I.; SARAVIS, V. Consideração sobre o idoso aposentado: uma intervenção da Terapia Cognitivo-Comportamental como instrumento de preparação à aposentadoria. Revista Brasileira de Ciências do Envelhecimento Humano v. 9, s.1. Passo Fundo, 2012. p. 90-101.

MORI, M. M.. Aposentadoria e trabalho: investigação sobre a (re)inserção do idoso no mercado de trabalho. 2006. Dissertação (Mestrado) - Pontifícia Universidade Católica de São Paulo. São Paulo: PUC, 2006.

PEREIRA NETTO, J. P.. Preparação para a aposentadoria: você já pensou nisso? São Paulo: Editora LTR, 2009.

SILVA, H. B. Preparação para aposentadoria: lições de ensinar e aprender fazendo. Serra: Companhia Siderúrgica de Tubarão, 2006. 148p.

SOARES, D. H. P.; COSTA, A. B.. Aposentação: aposentadoria para ação. São Paulo: Editora Vetor, 2011.

ZANELLI, J. C.; SILVA, N. Programa de preparação para a aposentadoria. Florianópolis: Insular, 1996 apud BOTH, T. L.; KUJAWA, D. R.; WOLBETO, M. I.; SARAVIS, V. Consideração sobre o idoso aposentado: uma intervenção da Terapia Cognitivo-Comportamental como instrumento de preparação à aposentadoria. Revista Brasileira de Ciências do Envelhecimento Humano v. 9, s.1. Passo Fundo, 2012. p. 90-101. 